\title{
Management of gastroesophageal reflux disease and erosive esophagitis in pediatric patients: focus on delayed-release esomeprazole
}

This article was published in the following Dove Press journal:

Therapeutics and Clinical Risk Management

20 October 2010

Number of times this article has been viewed

\section{Elizabet V Guimarães \\ Paula VP Guerra \\ Francisco J Penna}

Department of Pediatrics, Medical School, Universidade Federal de Minas Gerais, Belo Horizonte, Brazil
Correspondence: Elizabet V Guimarães Departamento de Pediatria, Faculdade de Medicina (Universidade Federal de Minas Gerais), Avenida Alfredo Balena, 190,

Santa Efigênia, Belo Horizonte, Brazil

$\mathrm{Tel}+5503$ I 34099772

Fax +55 03। 34099772

Email elizabet@medicina.ufmg.br
Objective: To review the literature on the treatment of gastroesophageal reflux disease (GERD) with emphasis on proton pump inhibitors (PPIs), particularly on delayed-release esomeprazole, and to identify properties and adverse effects of PPIs observed in the treatment of GERD in children and adolescents.

Sources: Electronic search of PubMed/Medline and Cochrane Collaboration databases, and of abstracts on DDW, NASPGHAN, and ESPGHAN. We focused on controlled and randomized studies published since 2000 and identified reviews that presented a consensual position, and directives published within the last 10 years.

Main results: PPIs are considered better antisecretory agents than $\mathrm{H}_{2}$-receptor antagonists. Although all PPIs are similar, they are not identical in their pharmacologic properties. For example, the acid-suppressive effect of esomeprazole, the S-isomer of omeprazole, persists for more than 16 hours after administration of the morning dose. Therefore, it can control acidity after night meals better than a single dose of omeprazole. Moreover, the onset of the suppressive effect of esomeprazole is faster. It achieves acid inhibition faster than other PPIs.

Conclusion: Currently, the mainstream treatment for GERD in children is a PPI. Although PPIs are safe drugs, effective in healing erosive esophagitis, and in relieving symptoms, studies with esomeprazole have shown that this drug has as powerful an ability to inhibit acid secretion as omeprazole. It also seems that some pharmacologic properties of esomeprazole are actually better for the treatment of GERD.

Keywords: gastroesophageal reflux, therapy, child, adolescent.

\section{Introduction}

The retrograde movement of gastric contents into the esophagus is a physiologic event called gastroesophageal reflux. Recently, evidence-based consensus has defined gastroesophageal reflux disease (GERD) in children. Consensus states that GERD in pediatric patients is present when the reflux of gastric contents is a cause of troublesome symptoms and/or complications. ${ }^{1,2}$ Symptoms of GERD vary with the age of the child. Heartburn and regurgitation are typical symptoms in adults and have high specificity for GERD. ${ }^{3}$ Many experts believe that these symptoms can be considered indicators of GERD in children older than eight years and in adolescents. ${ }^{4}$ However, in infants and preschool children, heartburn, regurgitation/vomiting, refusing feeding, excessive crying, and abdominal pain are often associated with GERD, but these symptoms lack specificity. ${ }^{5}$

Regurgitation is present in $50 \%$ of normal infants and it alone does not indicate the presence of GERD. Irritability and frequent crying are often normal events and are 
rarely related to GERD. ${ }^{6}$ Although the symptoms of GERD are less common than the symptoms of gastroesophageal reflux, the diagnosis of GERD is still prevalent. A prevalence study reported weekly heartburn sensation and acid regurgitation in approximately $2 \%$ of children aged 3-9 years and in 5\%-8\% of children aged 10-17 years. Heartburn alone was identified in $17.8 \%$ of the children in the older age group. ${ }^{7}$

Erosive esophagitis is defined as the presence of endoscopically visible breaks in the esophageal mucosa at or immediately above the gastroesophageal junction. In adults, only $30 \%$ of patients with GERD have erosive disease. ${ }^{8}$ In children without an underlying disease, as well as in adults, erosive disease should correspond to a smaller proportion of cases within the general framework of the disease. However, in children with underlying conditions that favor the disease (ie, esophageal atresia, severe neurologic disease, hiatal hernia, chronic lung disease, firstdegree relatives with severe GERD), erosive esophagitis is more frequent. Chronic and severe reflux esophagitis in children may develop complications as occurs in adults. Esophageal stenosis should be suspected in patients with chronic complaints of progressive dysphagia. Barrett's esophagus is very uncommon and it is mainly found when coexisting underlying conditions predispose to a chronic disease. $^{1}$

\section{Research strategy}

In 2006, we searched the PubMed/Medline and Cochrane Collaboration databases for the following keywords: gastroesophageal reflux and drug therapy, gastroesophageal reflux and omeprazole, lansoprazole, pantoprazole, ranitidine, cisapride, domperidone, metoclopramide, erythromycin; gastroesophageal reflux and esophagitis; gastroesophageal reflux and Barrett's esophagus; gastroesophageal reflux and respiratory tract diseases, gastroesophageal reflux, and cough; gastroesophageal reflux and asthma. ${ }^{9}$ Subsequently, a search was run on the same databases and on abstracts of Digestive Disease week, North American Society for Pediatric Gastroenterology, Hepatology and Nutrition, and European Society for Paediatric Gastroenterology, Hepatology and Nutrition, using the aforementioned words and esomeprazole. From these results, we selected controlled and randomized treatment studies, blind or otherwise, of children ( $<18$ years of age), published from 2000 onwards, and reviews that presented consensual positions or directives, published in the last 10 years. Other articles judged to be of relevance, including uncontrolled treatment studies and citations found in the selected articles, were also consulted and included when appropriate. When pediatric literature was considered to be scarce or nonexistent, the literature on adults was also consulted. This review was limited to articles published in English.

\section{Therapeutic management}

The therapeutic management of GERD includes lifestyle changes, pharmacologic therapy, and surgery.

\section{Lifestyle changes}

Patients with GERD may take advantage of changes in lifestyle with or without drug treatment. A supine position without elevation, for example, has been recommended, whereas other positions seem to have significant risks or do not present any advantages..$^{2,10,11-14}$ Thickened infant formula and the introduction of solid foods also reduce gastroesophageal reflux-related regurgitations. However, some studies have identified that the esophagus continues to be exposed to acid reflux. Furthermore, some infants may exhibit coughing or diarrhea as a consequence of thickened diets. ${ }^{10,15}$ Recommendations for older children and adolescents are based on those defined for adults. In terms of dietary restrictions, substances that cause an increased frequency of transitory lower esophageal sphincter relaxation or that are able to exacerbate symptoms should be avoided, including, eg, caffeine, chocolate, spicy foods, and alcohol. In addition, control of obesity, abstention from tobacco, and the suspension of passive smoking are also recommended. ${ }^{16}$

\section{Pharmacologic treatment}

\section{Principles of treatment}

In the treatment of GERD, the usual aims are to relieve symptoms, improve the patient's quality of life, heal mucosal lesions, and prevent recurrence and complications. The pharmacologic agents currently used for treating GERD in children are gastric acid buffering agents, prokinetics, and gastric antisecretory agents. Buffering agents are only used for the immediate relief of symptoms. Prokinetic agents were extensively used in the past because they increase the lower esophageal sphincter tonus. However, the pathophysiologic mechanism most strongly linked with GERD is increased frequency of transient relaxation of the lower esophageal sphincter. Because cisapride has been banned in most countries, these agents have been less frequently used. Currently, the major pharmacologic agents used for treating GERD are the gastric antisecretory agents. ${ }^{9}$ 


\section{Nonerosive esophagitis and suspected GERD}

Many clinical symptoms lead to the suspicion of GERD in infants and children. Although in certain circumstances it may not be the most likely diagnosis, in others, reflux esophagitis, particularly nonerosive esophagitis, is a consistent cause of complaints. Finding irritable infants is a very common situation in clinical practice, and because diagnostic tests are limited to predict GERD in this setting, ${ }^{17,18}$ infants with persistent crying and irritability may be managed in one of three ways, ie, parents may be told that improvement will occur over time, additional investigation may be recommended, and, finally, the use of drugs on a time-limited trial basis (two weeks) may be tried. However, empiric therapy has the potential risk of adverse effects, and clinical improvement may be due to spontaneous symptom resolution or to a placebo effect. ${ }^{2}$

Complaints of recurrent vomiting, abdominal pain, and dysphagia require corroborative diagnostic tests, usually upper endoscopy with biopsy (for differential diagnosis) or 24-hour esophageal $\mathrm{pH}$ monitoring.

Asthma is also a high prevalence disease and, within these patients, abnormal 24-hour $\mathrm{pH}$ manometry is usual. Furthermore, asthma and GERD may coexist without a causal relationship. GERD with esophageal symptoms should always be treated in patients with or without asthma, ${ }^{9}, 19-21$ and GERD should be considered a causal factor (precipitating or aggravating) of asthma only in difficult-to-treat cases (especially in patients with nocturnal symptoms of asthma and esophageal complaints). ${ }^{2}$ In these settings, the presence of clinical symptoms and tests confirming the pathologic presence of acid or nonacid contents in the esophagus, even without endoscopic changes, lead to the pharmacologic treatment of nonerosive esophagitis.

In contrast, children older than eight years of age and adolescents complaining of heartburn should be initially approached as having GERD, and pharmacologic treatment should be instituted without the need of further diagnostic tests. If regurgitation is also present, the specificity for GERD becomes even higher. ${ }^{1,3}$ Endoscopy should be performed only if the symptoms do not improve after 2-4 weeks of treatment, if there is resistance to drug withdrawal, or if the symptoms recur after discontinuation of medication. ${ }^{2}$ In all of these settings, treatment should be aimed at the suppression of gastric acidity, and in this case, proton pump inhibitor (PPIs) are the most recommended drugs.

GERD may or may not have a chronic course. ${ }^{22}$ Patients who have underlying diseases (ie, hiatal hernia, repaired esophageal atresia, central nervous system impairment, chronic lung disease) or who have first-degree relatives with severe and chronic illnesses are more likely to present this kind of evolution. ${ }^{23}$ In infants with GERD, one should wait for the acquisition of developmental marks associated with maturation of the antireflux barrier before discontinuing pharmacologic therapy. In other cases, GERD should be initially approached as a disease that can be treated with a 3-6-month course of pharmacologic treatment. Resistance to drug withdrawal and recurrence of symptoms points to a chronic course.

\section{Erosive esophagitis}

Gastric antisecretory agents are usually successful in treating GERD. It is possible that inadequate or delayed treatment of erosive esophagitis increases the risk of manifestation of other diseases, such as esophageal stricture. ${ }^{9}$ The main antisecretory agents currently used in children are PPIs and $\mathrm{H}_{2}$-receptor antagonists.

PPIs are considered better antisecretory agents than $\mathrm{H}_{2}$-receptor antagonists. A meta-analysis of studies in adults has shown that $77 \%$ of patients became symptom-free at eight weeks, compared with $48 \%$ of those taking $\mathrm{H}_{2}$-receptor antagonists. ${ }^{24}$ Moreover, other studies with adults have confirmed the superiority of PPIs over $\mathrm{H}_{2}$-receptor antagonists for healing severe esophagitis. However, for many years, only $\mathrm{H}_{2}$-receptor antagonists (especially ranitidine) were used in children, and until today there are few studies comparing the use of PPIs with $\mathrm{H}_{2}$-receptor antagonists in this age group.

In a randomized study, Cucchiara et al compared ranitidine with omeprazole. ${ }^{25}$ No significant difference in healing rates were observed between these groups. However, in their study, the dose of omeprazole was low $\left(40 \mathrm{mg} / 1.73 \mathrm{~m}^{2}\right)$ and the dose of ranitidine was very high $(20 \mathrm{mg} / \mathrm{kg} / \mathrm{day})$. Other studies have shown that a significant number of patients with esophagitis did not heal with such a low dose of omeprazole. ${ }^{26}$ Omeprazole at doses starting at $0.7 \mathrm{mg} / \mathrm{kg} / \mathrm{day}$ are already effective in healing esophageal erosion.

Hassal et al achieved healing of erosion with omeprazole doses ranging from 0.7 to $3.5 \mathrm{mg} / \mathrm{kg} /$ day. A $0.7 \mathrm{mg} / \mathrm{kg} /$ day dose cured esophagitis in $44 \%$ of patients and a $1.4 \mathrm{mg} / \mathrm{kg} /$ day dose healed it in $28 \%$ of patients. Cure occurred after $90 \pm 30$ days of reaching the healing dose. Symptoms improved within the first two weeks of treatment. ${ }^{26}$

Despite the need of further randomized and controlled trials in the use of PPIs, clinical experience with omeprazole keeps on growing. Lansoprazole was the second PPI to be cleared for pediatric use by the Food and Drug Administration (FDA), and it has been effective in healing esophageal 
erosion in children ${ }^{27}$ and adolescents. ${ }^{2}$ Thus, omeprazole is recommended at a dosage of $0.7-3.5 \mathrm{mg} / \mathrm{kg} /$ day, for an average period of three months. Lansoprazole, starting at a dosage of $15 \mathrm{mg} /$ day, partially improves symptoms of nonerosive esophagitis, and a dosage of $1.5 \mathrm{mg} / \mathrm{kg} /$ day or $30 \mathrm{mg} /$ day seems to be effective in healing esophageal erosion. ${ }^{27,28}$

In adults, besides omeprazole, other drugs such as lansoprazole, pantoprazole, rabeprazole, and esomeprazole have been used to treat GERD. ${ }^{8}$ Recently, studies with children using pantoprazole, ${ }^{29}$ rabeprazole,${ }^{30}$ and esomeprazole ${ }^{31}$ have also been published. ${ }^{32}$ PPIs currently approved for use in children in North America are omeprazole, lansoprazole, and esomeprazole. At the moment, only omeprazole and esomeprazole have been approved in Europe. No PPI has been approved for use in infants younger than one year of age.

In adults with erosive esophagitis, esomeprazole $40 \mathrm{mg}$ can offer higher healing rates when compared with those achieved by the standard doses of omeprazole $20 \mathrm{mg}$, lansoprazole $30 \mathrm{mg}$, and pantoprazole $40 \mathrm{mg} .{ }^{33-36}$

Recently, improvement of symptoms in adolescents clinically diagnosed with GERD was evaluated using $20 \mathrm{mg}$ and $40 \mathrm{mg}$ of esomeprazole. Symptom scores decreased significantly in both groups by the final week of treatment. At baseline, $63.1 \%$ of patients had moderate to severe symptoms, while at the final visit, this number decreased to $9.3 \%(P<0.0001) .{ }^{37}$ Similarly, improvement of symptoms were tested in children with endoscopically proven GERD using esomeprazole. Patients aged 1-11 years received $5 \mathrm{mg}$ or $10 \mathrm{mg}$ of esomeprazole if they weighed less than $20 \mathrm{~kg}$, and $10 \mathrm{mg}$ or $20 \mathrm{mg}$ if they weighed more than $20 \mathrm{~kg}$. Of the 58 patients with moderate to severe symptoms, $91.4 \%$ had improved by the final week of treatment. $^{31}$

It is usual for GERD to relapse when treatment is withdrawn. Approximately $80 \%$ of adult patients relapse after six to 12 months, requiring the long-term use of gastric acid suppressants. $^{38}$

It is important to point out that the most common errors when prescribing PPIs are subtherapeutic dosages, and failure to follow the recommendations about administration. PPIs must be taken once a day before breakfast. Administration to young children requires opening the enteric-coated capsules, and the contents must be diluted in acid beverages, according to some authors. ${ }^{39}$

In case of limited response to treatment, one should review the prescribed dosage, verify if there has been compliance with treatment, and check the diagnosis. Eosinophilic esophagitis should always be kept in mind in such cases.
Maintenance therapy is still under discussion. After the healing of erosive esophagitis, adults with mild symptoms can be managed with on-demand therapy. Boccia et al studied children with erosive esophagitis and found no difference in recurrence of esophagitis and symptoms in children on maintenance therapy with omeprazole (half of the dose used during the healing phase of the injury), in those on maintenance therapy with ranitidine, and in those not using any drugs. The presence of an underlying condition that might be triggering the development of a chronic disease should be considered when prescribing maintenance therapy. ${ }^{40}$

Evaluation of cost-effectiveness is also a relevant aspect and should be considered in the choice of starting and maintaining treatment schemes. The estimated annual cost of PPI use is several billion dollars. ${ }^{41}$ In adults, on-demand strategies present the best cost-effectiveness relation for maintenance treatment of GERD, especially for those adults with mild symptoms. ${ }^{41,42}$ Studies, in children, evaluating success rate, cost-effectiveness, and risks of the different treatment schemes are scarce. Hopefully, in the near future, such studies will be able to guide GERD treatment in pediatrics.

\section{PPIs and $\mathbf{H}_{2}$-receptor antagonists}

The postprandial acid inhibition produced by $\mathrm{H}_{2}$-receptor antagonists is only partial. In contrast, PPIs are able to inhibit meal-induced acid secretion. Gastric $\mathrm{pH}$ begins to increase within 30 minutes of administration of $\mathrm{H}_{2}$-receptor antagonists, and acid suppression lasts 4-8 hours. ${ }^{8}$ Most available PPIs are therefore regarded as "delayed-release" preparations, and maximal acid suppressant effect can take up to four days to be reached. However, PPIs maintain intragastric $\mathrm{pH} \geq 4$ for longer periods of time. Reduction of acid secretion caused by $\mathrm{H}_{2}$-receptor antagonists is less pronounced and lasts less time than that caused by PPIs, but $\mathrm{H}_{2}$-receptor antagonists are better for the immediate relief of symptoms. ${ }^{2,8}$

The powerful action of PPIs, in addition to elevating gastric $\mathrm{pH}$, also leads to reducing 24-hour intragastric volume, facilitating gastric emptying, and reducing refluxate volume. The only PPIs used in children are enteric-coated capsules and the multiple-unit pellet system. The capsules contain delayed-release granules, which should not be chewed or ground up because they are acid-labile. There is no liquid preparation. The ideal regime for a PPI is one dose a day, before the first meal, because that is when proton pumps are generated and can be most effectively blocked. A second dose may be recommended with the evening meal in the presence of severe esophagitis, peptic stricture, esophageal motility 
disorders, persistent nocturnal reflux, and extraesophageal GERD. However, data on extraesophageal GERD are inconclusive and more studies are needed to assess treatment regimens. ${ }^{43}$

Tolerance has been observed with $\mathrm{H}_{2}$-receptor antagonists, but not with PPIs. Ranitidine can induce tolerance within five days of use. ${ }^{44}$ Tolerance is probably due to increase of gastrin. PPIs act at the final site of acid production, so these drugs block the effect of any compensatory mechanisms promoting acid secretion. ${ }^{45}$

PPIs are similar drugs but not identical in their pharmacologic properties. Esomeprazole is the S-isomer of omeprazole. It inhibits acid production faster than other PPIs $^{46}$ and, as a result, there is faster symptom relief. Clinically relevant benchmark effects on acid secretion include the magnitude of this effect, the consistency of this effect amongst individuals, and the duration over which the desired effect is maintained. Compared with omeprazole $20 \mathrm{mg}$, esomeprazole $20 \mathrm{mg}$ and $40 \mathrm{mg}$ have been shown to produce superior outcomes on these three key measures of antisecretory effect. ${ }^{47}$ However, the clinical relevance of these effects, particularly for patients with nonerosive esophagitis, is not yet clear. The pharmacokinetic properties of esomeprazole have been evaluated in adolescents, children, infants, preterm infants, and term neonates with GERD. ${ }^{31,37,47-49}$ Despite the small number of patients involved in these studies, the pharmacokinetic parameters of esomeprazole proved to be dose- and time-dependent, and this might be due to the fact that young children have a faster metabolism of esomeprazole per kilogram of body weight than older children. In preterm infants and term neonates, esomeprazole produces no changes in the characteristics of the bolus reflux despite its significant acid suppression effects. ${ }^{49}$ It can be concluded that esomeprazole, in children, can have the same advantages of GERD treatment observed in adults. The magnitude of this acid-suppressive effect persists for more than 16 hours after the morning dose, allowing control of esophageal acidity after night meals. ${ }^{47}$ Moreover, the onset of the suppressive effect is faster with esomeprazole. In adults, responses vary much less among individuals than with omeprazole. This effect cannot be observed in young infants up to 12 months of age. ${ }^{49}$ Whilst having similar structures, PPIs differ in their metabolism. PPIs, mainly omeprazole, are metabolized to different degrees by the $\mathrm{P} 450$ hepatic enzyme system, specifically by the CYP2C19 and CYP3A4 enzymes. Significant features of the pharmacokinetics and pharmacodynamics of PPIs are related to the genetic polymorphism of these enzymes, which affects the biotransformation and plasma elimination of PPIs. Genetic polymorphism can lead to major differences in the kinetics of PPIs. Individuals who metabolize these drugs poorly may experience greater effects of the dose used. Thus, a proportion of the great variation observed in PPI trials in children could be explained by these findings. ${ }^{50,51}$

Adverse effects related to PPIs in children include headaches, diarrhea, abdominal pain, nausea, skin rash, constipation, elevated transaminase levels, and proteinuria. ${ }^{51}$ Recently, the safety of esomeprazole $20 \mathrm{mg}$ and $40 \mathrm{mg}$ were evaluated in 148 adolescents with GERD. Adverse events were reported by $75 \%$ and $78 \%$ of the patients, respectively. However, only $14.9 \%$ of the adverse effects were considered related to the treatment. ${ }^{37}$ In children aged 1-11 years with GERD and treated with esomeprazole, none of the adverse effects that occurred were considered related to treatment. ${ }^{31}$ Acid suppression due to the use of $\mathrm{H}_{2}$-receptor antagonists and PPIs may be associated with community-acquired pneumonia and gastroenteritis in children. ${ }^{52}$ In adults, PPIs have been shown to alter the gastric and intestinal microbiota $^{53}$ and to cause acute interstitial nephritis. ${ }^{54}$ In children, this effect has not been reported. Hypergastrinemia and parietal cell hyperplasia have been observed with PPIs. However, these findings do not have any clinically relevant implications. ${ }^{51}$

Because PPIs are sometimes administered simultaneously with many drugs, it is important to consider their interactions with other drugs. As a result of the intense reduction in gastric acidity, PPIs can reduce the bioavailability of drugs that require lower $\mathrm{pH}$ values to be absorbed, such as ampicillin, cyanocobalamin, iron, digoxin, and ketoconazole.

\section{Conclusion}

Current treatment of GERD is based on the use of gastric antisecretory drugs, mainly PPIs. Delayed-release esomeprazole retains the powerful gastric inhibitory action of omeprazole, but has longer lasting effects and is faster in the onset of its effects. In a single-administration scheme, esomeprazole may have advantages over other PPIs. No adverse effects, different from the already known effects of PPIs, have been observed, so far, in studies with children and adolescents. However, the number of randomized controlled therapeutic trials in children is still small. Future studies should take down the current statements for the disease so that the outcome variables can be compared. Surgery may be recommended in very specific cases as an adjuvant treatment with PPIs. 


\section{Disclosure}

The authors report no conflicts of interest in this work.

\section{References}

1. Sherman PM, Hassall E, Fagundes-Neto U, et al. A global, evidencebased consensus on the definition of gastroesophageal reflux disease in the pediatric population. Am J Gastroenterol. 2009;104:1278-1295.

2. Vandenplas Y, Rudolph CD, Di Lorenzo C, et al. Pediatric gastroesophageal reflux clinical practice guidelines: joint recommendations of the North American Society for Pediatric Gastroenterology, Hepatology, and Nutrition (NASPGHAN) and the European Society for Pediatric Gastroenterology, Hepatology, and Nutrition (ESPGHAN). J Pediatr Gastroenterol Nutr. 2009;49:498-547.

3. Vakil N, van Zanten SV, Kahrilas P, Dent J, Jones R. Global Consensus Group. The Montreal definition and classification of gastroesophageal reflux disease: A global evidence-based consensus. Am J Gastroenterol. 2006;101:1900-1920.

4. Gunasekaran TS, Dahlberg M, Ramesh P, Namachivayam G. Prevalence and associated features of gastroesophageal reflux symptoms in a Caucasian-predominant adolescent school population. Dig Dis Sci. 2008;53:2373-2379.

5. Moore DJ, Tao BS, Lines DR, Hirte C, Heddle ML, Davidson GP. Double-blind placebo-controlled trial of omeprazole in irritable infants with gastroesophageal reflux. J Pediatr. 2003;143:219-223.

6. Armstrong K, Previtera N, McCallum R. Medicalizing normality? Management of irritability in babies. J Paediatr Child Health. 2000; 36:301-305.

7. Nelson SP, Chen EH, Syniar GM, Christoffel KK. Prevalence of symptoms of gastroesophageal reflux during childhood: A pediatric practice-based survey. Pediatric Practice Research Group. Arch Pediatr Adolesc Med. 2000;154:150-154.

8. Savarino V, di Mario F, Scarpignato C. Proton pump inhibitors in GORD: An overview of their pharmacology, efficacy and safety. Pharmacol Res. 2009;59:135-153.

9. Guimarães EV, Marguet C, Camargos PAM. Treatment of gastroesophageal reflux disease. J Pediatr (Rio J). 2006;82 Suppl 5:S133-S145.

10. Craig WR, Hanlon-Dearman A, Sinclair C, Taback S, Moffatt M. Metoclopramide, thickened feedings, and positioning for gastrooesophageal reflux in children under two years. Cochrane Database Syst Rev. 2004;CD003502.

11. Tobin JM, McCloud P, Cameron DJ. Posture and gastrooesophageal reflux: A case for left lateral positioning. Arch Dis Child. 1997; 76:254-258

12. Oyen N, Markestad T, Skaerven R, et al. Combined effects of sleeping position and prenatal risk factors in sudden infant death syndrome: The Nordic Epidemiological SIDS Study. Pediatrics. 1997;100:613-621.

13. Jeffery HE, Megevand A, Page H. Why the prone position is a risk factor for sudden infant death syndrome. Pediatrics. 1999;104(2 Pt 1): 263-269.

14. Bagucka B, de Schepper J, Peelman M, van de Maele K, Vandenplas Y. Acid gastro-esophageal reflux in the 10 degrees reversedTrendelenburg-position in supine sleeping infants. Acta Paediatr Taiwan. 1999;40:298-301.

15. Wenzl TG, Schneider S, Scheele F, Silny J, Heimann G, Skopnik H. Effects of thickened feeding on gastroesophageal reflux in infants: A placebo-controlled crossover study using intraluminal impedance. Pediatrics. 2003;111(4 Pt 1):e355-e359.

16. Rudolph CD, Mazur LJ, Liptak GS, et al. Guidelines for evaluation and treatment of gastroesophageal reflux in infants and children: Recommendations of the North American Society for Pediatric Gastroenterology and Nutrition. J Pediatr Gastroenterol Nutr. 2001;32 Suppl 2: S1-S31.

17. Vandenplas Y, Badriul H, Verghote $\mathrm{M}$, et al. Oesophageal $\mathrm{pH}$ monitoring and reflux oesophagitis in irritable infants. Eur J Pediatr. 2004; 163:300-304.
18. Heine RG, Cameron DJ, Chow CW, et al. Esophagitis in distressed infants: Poor diagnostic agreement between esophageal $\mathrm{pH}$ monitoring and histopathologic findings. J Pediatr. 2002;140:14-19.

19. Scarupa MD, Mori N, Canning BJ. Gastroesophageal reflux disease in children with asthma: Treatment implications. Paediatr Drugs. 2005; 7:177-186.

20. Condino AA, Sondheimer J, Pan Z, et al. Evaluation of gastroesophageal reflux in pediatric patients with asthma using impedance-pH monitoring. J Pediatr. 2006;149:216-219.

21. Stordal K, Johannesdottir GB, Bentsen BS, et al. Acid suppression does not change respiratory symptoms in children with asthma and gastro-oesophageal reflux disease. Arch Dis Child. 2005;90:956-960.

22. Gold BD. Is gastroesophageal reflux disease really a life-long disease: Do babies who regurgitate grow up to be adults with GERD complications? Am J Gastroenterol. 2006;101:641-644.

23. Hassall E, Kerr W, El-Serag HB. Characteristics of children receiving proton pump inhibitors continuously for up to 11 years duration. J Pediatr. 2007;150:262-267.

24. Chiba N, de Gara CJ, Wilkinson JM, Hunt RH. Speed of healing and symptom relief in grade II to IV gastroesophageal reflux disease: A meta-analysis. Gastroenterology. 1997;112:1798-1810.

25. Cucchiara S, Minella R, Iervolino C, et al. Omeprazole and high dose ranitidine in the treatment of refractory reflux oesophagitis. Arch Dis Child. 1993;69:655-659.

26. Hassall E, Israel D, Shepherd R, et al. Omeprazole for treatment of chronic erosive esophagitis in children: A multicenter study of efficacy, safety, tolerability and dose requirements. International Pediatric Omeprazole Study Group. J Pediatr. 2000;137:800-807.

27. Franco MT, Salvia G, Terrin G, et al. Lansoprazole in the treatment of gastro-oesophageal reflux disease in childhood. Dig Liver Dis. 2000; 32:660-666.

28. Fiedorek S, Tolia V, Gold BD, et al. Efficacy and safety of lansoprazole in adolescents with symptomatic erosive and non-erosive gastroesophageal reflux disease. J Pediatr Gastroenterol Nutr. 2005;40:319-327.

29. Tsou VM, Baker R, Book L, et al. Multicenter, randomized, doubleblind study comparing 20 and $40 \mathrm{mg}$ of pantoprazole for symptom relief in adolescents (12 to 16 years of age) with gastroesophageal reflux disease (GERD). Clin Pediatr (Phila). 2006;45:741-749.

30. James L, Walson P, Lomax K, Kao R, Varughese S, Reyes J. Pharmacokinetics and tolerability of rabeprazole sodium in subjects aged 12 to 16 years with gastroesophageal reflux disease: An open-label, single- and multiple-dose study. Clin Ther. 2007;29:2082-2092.

31. Gilger MA, Tolia V, Vandenplas Y, Youssef NN, Traxler B, Illueca M. Safety and tolerability of esomeprazole in children with gastroesophageal reflux disease. J Pediatr Gastroenterol Nutr. 2008;46: 524-533.

32. Furuta GT, Liacouras CA, Collins MH, et al. Eosinophilic esophagitis in children and adults: A systematic review and consensus recommendations for diagnosis and treatment. Gastroenterology. 2007;133: 1342-1363.

33. Castell DO, Kahrilas PJ, Richter JE, et al. Esomeprazole (40 mg) compared with lansoprazole $(30 \mathrm{mg})$ in the treatment of erosive esophagitis. Am J Gastroenterol. 2002;97:575-583.

34. Fennerty MB, Johanson JF, Hwang C, et al. Efficacy of esomeprazole $40 \mathrm{mg}$ versus lansoprazole $30 \mathrm{mg}$ for healing moderate to severe erosive esophagitis. Aliment Pharmacol Ther. 2005;21:455-463.

35. Kahrilas PJ, Falk GW, Johnson DA, et al. Esomeprazole improves healing and symptom resolution as compared with omeprazole in reflux esophagitis patients: A randomized controlled trial. Aliment Pharmacol Ther. 2000;14:1249-1258.

36. Richter JE, Kahrilas PJ, Johanson J, et al. Efficacy and safety of esomeprazole compared with omeprazole in GERD patients with erosive esophagitis: A randomized controlled trial. Am J Gastroenterol. 2001;96:656-665.

37. Gold BD, Gunasekaran T, Tolia V, et al. Safety and symptom improvement with esomeprazole in adolescents with gastroesophageal reflux disease. J Pediatr Gastroenterol Nutr. 2007;45:520-529. 
38. Moayyedi P, Talley NJ. Gastro-oesophageal reflux disease. Lancet. 2006;367:2086-2100.

39. Tafuri G, Trotta F, Leufkens HG, Martini N, Sagliocca L, Traversa G. Off-label use of medicines in children: Can available evidence avoid useless paediatric trials? The case of proton pump inhibitors for the treatment of gastroesophageal reflux disease. Eur J Clin Pharmacol. 2009;65:849-850.

40. Boccia G, Manguso F, Miele E, Buonavolontà R, Staiano A. Maintenance therapy for erosive esophagitis in children after healing by omeprazole: Is it advisable? Am J Gastroenterol. 2007;102:1291-1297.

41. Gerson LB, Robbins AS, Garber A, Hornberger J, Triadafilopoulos G. A cost-effectiveness analysis of prescribing strategies in the management of gastroesophageal reflux disease. Am J Gastroenterol. 2000;95: 395-407.

42. Heidelbaugh JJ, Goldberg KL, Inadomi JM. Overutilization of proton pump inhibitors: A review of cost-effectiveness and risk. Am J Gastroenterol. 2009;104 Suppl 2:S27-S32.

43. Hassall E. Decisions in diagnosing and managing chronic gastroesophageal reflux disease in children. J Pediatr. 2005;146 Suppl 3:S3-S12.

44. Lachman L, Howden CW. Twenty-four-hour intragastric $\mathrm{pH}$ : Tolerance within 5 days of continuous ranitidine administration. Am J Gastroenterol. 2000;95:57-61.

45. Sandvik AK, Brenna E, Waldum HL. Review article: The pharmacological inhibition of gastric acid secretion: tolerance and rebound. Aliment Pharmacol Ther. 1997;11:1013-1018.
46. Pantoflickova D, Dorta G, Ravic M, Jornod P, Blum AL. Acid inhibition on the first day of dosing: Comparison of four proton pump inhibitors. Aliment Pharmacol Ther. 2003;17:1507-1514.

47. Dent J. Review article: Pharmacology of esomeprazole and comparisons with omeprazole. Aliment Pharmacol Ther. 2003;17 Suppl 1:5-9.

48. Omari T, Davidson G, Bondarov P, Nauclér E, Nilsson C, Lundborg P. Pharmacokinetics and acid-suppressive effects of esomeprazole in infants 1-24 months old with symptoms of gastroesophageal reflux disease. J Pediatr Gastroenterol Nutr. 2007;45:530-537.

49. Omari T, Lundborg P, Sandström M, et al. Pharmacodynamics and systemic exposure of esomeprazole in preterm infants and term neonates with gastroesophageal reflux disease. J Pediatr. 2009;155:222-228.

50. Klinkenberg-Knol EC, Nelis F, Dent J, et al. Long-Term Study Group. Long-term omeprazole treatment in resistant gastroesophageal reflux disease: Efficacy, safety, and influence on gastric mucosa. Gastroenterology. 2000;118:661-669.

51. Marchetti F, Gerarduzzi T, Ventura A. Proton pump inhibitors in children: A review. Dig Liver Dis. 2003;35:738-746.

52. Canani RB, Cirillo P, Roggero P, et al. Therapy with gastric acidity inhibitors increases the risk of acute gastroenteritis and communityacquired pneumonia in children. Pediatrics. 2006;117:e817-e820.

53. Williams C, McColl KE. Review article: Proton pump inhibitors and bacterial overgrowth. Aliment Pharmacol Ther. 2006;23:3-10.

54. Brewster UC, Perazella MA. Proton pump inhibitors and the kidney: Critical review. Clin Nephrol. 2007;68:65-72.
Therapeutics and Clinical Risk Management

\section{Publish your work in this journal}

Therapeutics and Clinical Risk Management is an international, peerreviewed journal of clinical therapeutics and risk management, focusing on concise rapid reporting of clinical studies in all therapeutic areas, outcomes, safety, and programs for the effective, safe, and sustained use of medicines. This journal is indexed on PubMed Central, CAS,

\section{Dovepress}

EMBase, Scopus and the Elsevier Bibliographic databases. The manuscript management system is completely online and includes a very quick and fair peer-review system, which is all easy to use. Visit http://www.dovepress.com/testimonials.php to read real quotes from published authors. 